\title{
Optimization of Driving Trailers Transmission for Peat Transportation
}

\author{
Alexander Yablonev ${ }^{1, *}$, Igor Gorlov ${ }^{1}$, Larisa Kozyreva ${ }^{1}$, and Konstantin Fomin ${ }^{1}$ \\ ${ }^{1}$ Tver State Technical University (TvSTU), 170026, Afanasiy Nikitin emb., 22, Tver, Russia
}

\begin{abstract}
Improving the performance of transport tractor units in operations for removing peat from production areas is associated with increased body trailers that require the use of drive type trailers with active front wheels. When designing such trailers there were difficulties in determining the transmission ratio and transmission scheme, especially in the case of using tractors with different passport interpretations of a synchronous operating mode with the power take-off shaft (PTS). The article presents the method of calculating the transmission ratio of the drive type trailers depending on the parameters of a synchronous operating mode the power take-off shaft of the tractor. The principle kinematic scheme of driving trailers is justified. Recommendations on selection of transmission units are given.
\end{abstract}

\section{Introduction}

The development of peat industry in all countries of the world follows the economic and ecological factors, which are availability, low cost and the possibility of multi-use peat $[1$, 2]. The most important stage of peat production is peat transportation from production sites. And we are talking not only about the transport of peat collected in piles, but its delivery to the consumer. The lack of normal automobile roads in the area of marshes forces to search for the most appropriate ways of delivering peat by means of narrow-gauge railways and tractor-transport units, because to use automobile transport is only possible in winter when roads are frozen. But the maintenance of the internal railways is highly costly action, significantly raising the price of the product [3]. Therefore, build transport module peat company should rely primarily on their own strength and technique involved at both the harvesting and transport operations [4]. Such techniques are wheeled tractors with trailers. Body capacity trailer is a determinant of their economic efficiency [5]. However, the increasing capacity of the body leads to an increase in the load on the wheel running, resulting in losing permeability by the tractor transport unit $[6,7]$. This is true not only for peat mining, but also for other conditions when operating the various caterpillar and wheel technics on soils with low bearing capacity, for example in the agricultural and forest sector $[8,9]$.

\footnotetext{
* Corresponding author: alvovich@mail.ru
} 


\section{Materials and methods}

Modeling and calculation of interaction of the one-axle passive trailers pneumatic wheel running on peat deposits like working bodies of forestry machinery [10] led to the justification of the maximum possible capacity of a passive body trailer $\left(25 \mathrm{~m}^{3}\right)$ on the condition of the coupling and bearing permeability. With this in mind that bearing capacity of high moisture peat deposit is much lower than black earth and organogenic rock, such as lignin [11-13]. But found body capacity does not allow achieving high efficiency of the peat harvesting production operations, especially when using a separate method of harvesting larger rollers (HLR), involving continuous type loaders with high productivity [14].

The solution can be found in the development and application of not passive, but driven trailers (Fig. 1).

Through the use of two axles in this trailer, the load on the wheels is reduced, and therefore - the pressure on peat deposit is reduced. The front wheels of the trailer - power transmission, which increases the permeability of the tractor and transport unit. This integrated solution can provide transportation of $45-50 \mathrm{~m}^{3}$ milled peat with moisture content of $45-50 \%$.

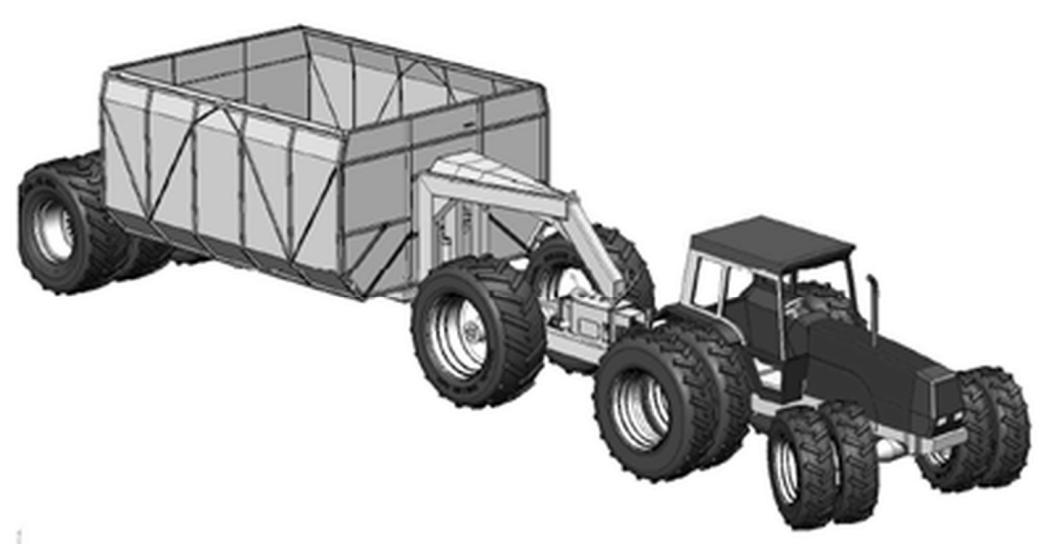

Fig. 1. Driving trailer for peat transportation.

Transfer torque to the front axle of the trailer is driven by the power take-off of the tractor, working in the mode of "synchronous drive". But the consistency of tractor and trailer transmissions, in particular, the selection of adequate gear ratio transmission remains complex and poorly studied issue. To reduce construction costs of the trailer transmission it is desirable to use universal parts and assembly units (gears, cardan shafts, bridge, etc.). It should be noted, however, that not all tractors have the function of synchronous work of the PTS. Therefore, the problem of calculating the transmission ratio of trailers and choice of used units is very actual and important. Especially, it should be taken into consideration that peat production is connected with a very short and warm summer season.

\section{Results and Discussion}

Such tractors as MTZ, VALTRA, HTZ, John Deer, VTZ and others are used in peat production. But not all of them have the function of power take-off shaft in synchronous mode. For example, VALTRA and MTZ-1221 tractors have such an option. Both of these 
tractors have been successfully used by peat extractive companies. But data about synchronous modes are presented in the passports of tractors in various ways. For tractor VALTRA this mode is described as "turnover 40.81 PTS for 1 rear wheel turnover" in specification. Technical characteristic of MTZ-1221, synchronous mode of work presented in the form of "4.18 turnover PTS for 1 meter path" when using the wheels 18.4R38. Despite the difference of this mode in the passport documentation of tractors, however, it is one and the same synchronization process of PTS and driving wheels rotational speed.

The value is represented as a "turnover 40.81 PTS for 1 rear wheel turnover" - rigid ratio between PTS and tractors rear semi-major axles $i_{t}$. Therefore, if the diameter of the wheels of the tractor $D_{t}$ and trailer $D_{m}$ is equal, the total gear ratio transmission trailer $i_{m}$ must be equal to the ratio $i_{t}$. But since this is not so in most cases, the correction factor must be used in calculation, taking into account the difference between the diameters of the tractor driving wheels and trailer:

$$
i_{m}=i_{t} D_{m} / D_{t}
$$

For example, when combining VALTRA N82h and N92h, equipped with tires 18,4R34 $\left(D_{t}=1,575 \mathrm{~m}\right)$ and driving trailers equipped with tires $18,4 R 30\left(D_{m}=1,540 \mathrm{~m}\right)$, the total ratio of the trailer:

$$
i_{m}=40.811 .540 / 1.575=39.9031
$$

This is logical, because the trailer wheel, being a smaller diameter than the tractor one, for 1 meter path makes more rotations than tractors wheel, consequently, the total transmission ratio of the trailer must be less than rigid ratio between PTO and semi-major axles of the tractor.

Several different situation with the tractor type MTZ-1221, PTO is synchronous speed $n_{o}=4.18$ rotation for 1 meter path when using the rear driving wheels with tires 18.4R38 $\left(D_{t}=1.76 \mathrm{~m}\right)$.

The first thing that is necessary to find out is what in this case a rigid ratio between PTO and semi-major axles driving rear wheel tractor $i_{t}$. We will use the following special considerations. Path $l$, which will take the wheel of a tractor for one full rotation depending on wheels diameter:

$$
l=\pi D_{t},
$$

Calculate it by substituting in (2) available data:

$$
l=3.14159 \times 1.76=5.5292 \mathrm{~m} \text {. }
$$

During one full rotation of the wheel tractor, PTO shaft will do the required number of rotations $n_{l}$ :

$$
\begin{gathered}
n_{1}=n_{o} l \\
n_{1}=4,18 \times 5,5292=23,1121 \text { rotations. }
\end{gathered}
$$

Dividing the number of rotations of the PTO shaft on 1 turnover drive wheel get that rigid ratio between PTO and semi-major axles of the tractor:

$$
\begin{gathered}
i_{t}=n_{1} / 1 \\
i_{t}=23,1121 .
\end{gathered}
$$

Then the ratio of the trailer, according to (1): 


$$
i_{m}=23.1121 \times 1.54 / 1.76=20.2231 .
$$

As in the case of tractor VALTRA, smaller diameter wheel trailer for 1 meter path should make more rotations than the tractor wheel. Consequently, the overall transmission ratio of the trailer must be less than rigid ratio between PTO shaft and semi-major axles of the tractor. Substituting into (1) expression (2), (3) and (4), we get:

$$
i_{m}=n_{o} \pi D_{t} D_{m} / D_{t}=n_{o} \pi D_{m}
$$

Therefore, in the case of reporting on synchronous frequency of the drive as "... PTO speed for 1 meter path", the overall transmission ratio of the drive the trailer can be found using only the diameter of the wheels. This is true if the tractor wheel unchanged and correspond to the passport characteristics, namely it must be so.

Found higher overall gear ratio is the first item matching trailer transmission units. Obviously, the second step is a selection of widespread driving bridge, which has its internal ratio of $i_{3}$. It should be noted here that the choice should be made among the driving truck bridge with similar carrying capacity for the trailer. The step should be considered as a choice of type and ratio of the input $i_{1}$ and, if necessary, intermediate $i_{2}$ gearboxes.

The principle kinematic scheme of transmission drive trailer, described above is presented in fig. 2.

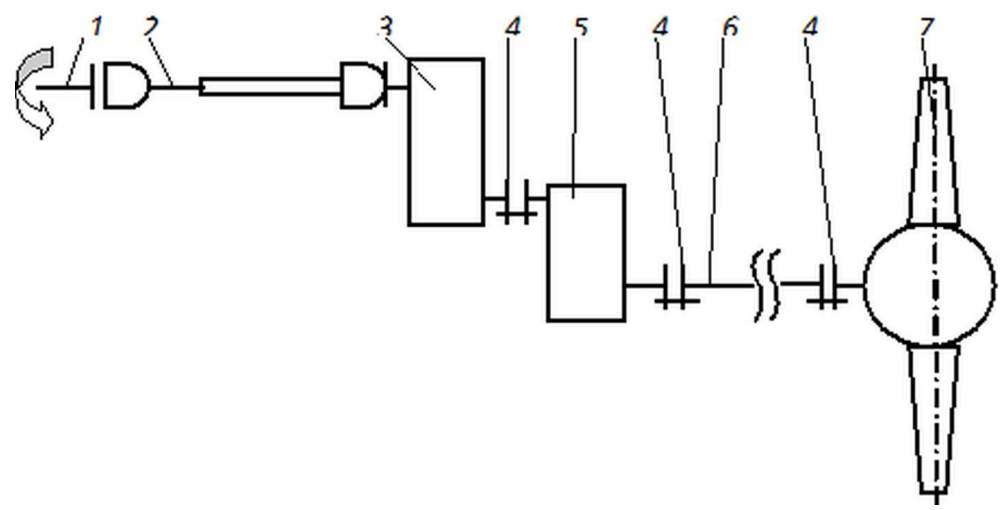

Fig. 2. Principle kinematic scheme of transmission drive trailer:

1 - the power take-off shaft of the tractor with the synchronous mode of operation; 2 - driveline; 3 the input reducer; 4 - coupling;

5 - intermediate gear; 6 - transmission shaft; 7 -drive axle

The total ratio of the trailers transmission $i_{m}$ represents the product of ratios of individual elements of the drivetrain:

$$
i_{m}=i_{1} i_{2} i_{3}
$$

As input we can recommend the use of a cylindrical vertical reducer (fig. 3), widespread, for example, in the machines of continuous transport [15]. The necessity for using in transmission planet gear machines, its high cost, may be due to the only clear advantages, which gives planetary gear: high gear ratio with small diameters of shafts and compactness. 


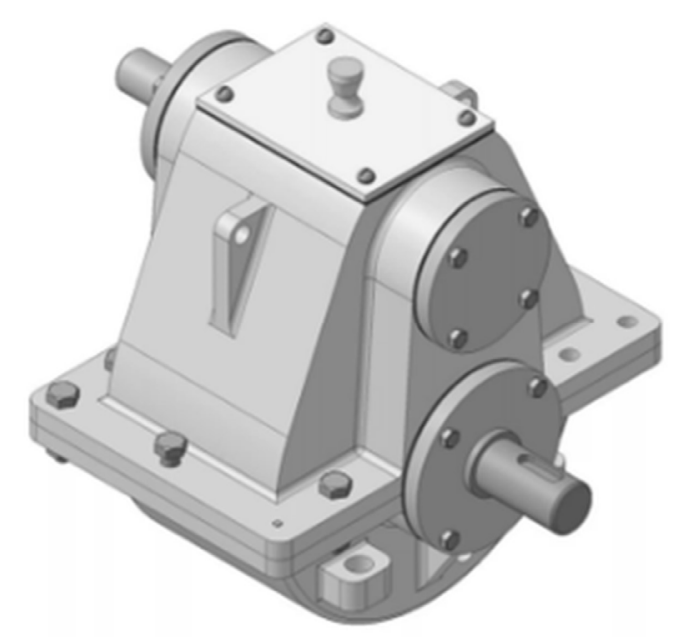

Fig. 3. The cylindrical vertical reducer

\section{Conclusion}

Methods for calculating the transmission ratio of driving trailers, shown in the article just for traffic conditions of wheels of tractor and trailer with the same deformation and slippage when wheels dynamic radius tractor and trailer are equal. From this it follows that the outer diameter of the wheels of trailer should be selected as close as possible to the outer diameter of tractor' wheels. Since radial deformation depends on the vertical load and air pressure in the tires, then modifying these parameters at the design stage, we can achieve the same skidding, and, therefore, the same dynamic radius. Little difference in wheel skidding does lend itself to smoothing by imposing in the composition of the transmission trailer outrunning muff, which would allow the trailer to push tractor with strong slipping of its wheels.

Switching off the power take-off shaft of the tractor drive leads to shutdown of drive transmission trailer. The movement of the unit rear-enabled transfer is possible, because the PTO shaft synchronous mode is not driven from the crankshaft of the engine of tractor, but from the secondary shaft of the gearbox. Therefore, rotation in the opposite direction of the secondary shaft causes the opposite of directional rotation of the PTO shaft.

Based on the foregoing, the following inferences can be drawn. A different view of a synchronous operating mode, the PTO shaft of the tractor in passports is a consequence of one and the same process - the sync shaft rotation frequency and the frequency of rotation of the driving wheels. Equations (1) and (5) to select the gear ratio transmission driving trailers are received. Principle kinematic scheme of driving trailer is compiled. It should be noted that when designing a tractor transport unit it should be installed on the trailer wheels the diameter of which would be close to the diameter of the rear wheels of the tractor, and strive for the same project of skidding.

\section{References}

1. J. Korpi, Proceed.13-th Int. Peat Cong., Tullamore, Ireland, 1, 120-122 (2008)

2. O. Misnikov, E3S Web. Conf., 21, 01013 (2017) 
3. A. Tyurin, E3S Web. Conf., 21, 01020 (2017)

4. E.A. Kremcheev, D.O. Nagornov, Life Science Journal. 11:11s, 453-456 (2014)

5. G. Alexandrov, A. Yablonev, E3S Web Conf. 21, 04011 (2017)

6. J.C. Larminie, J. of Terramechanics, 29:2, 239-255 (1992)

7. F. Mainardi, G. Spanda, The Eur. Phys. J., Spec. Topics, 193, 133-160 (2011)

8. K.-J. Jansson, J. Johansson, Forestry, 1, 57-66 (1998)

9. D. Rees, Basic Engeneering Plasticity. An Introduction with Engineering and Manufacturing Applications (Butter Worth, Heinemann, 2006)

10. J.X. Wang, C.B. Le Doux, C.B., Y,X. Li, Int. J. of Forest Engineering, 16:2, 77-85 (2005)

11. J.Y. Wong, A.R. Reece, Proceed. 2-th Int. Conf. of the Int. Society for Terrain Vehicle Syst., Toronto Press, Toronto, Canada, 1, 37-52 (1966)

12. M.G. Bekker, Theory of land locomotion (The mechanics of vehicle mobility). (Michigan University Press, Michigan, 1956)

13. J.Y. Wong, Theory of ground vehicles (John Wiley and Sons, Ontario, 1982)

14. V.V. Panov, O.S. Misnikov, Min. J., 7, 108-112 (2015)

15. O. S. Misnikov, V. V. Panov, Journal of Mining and Geotechnical Engineering, 1, 4255 (2018) DOI: 10.26730/2618-7434-2018-1-42-55 